\title{
Ovine clone ST1464: A predominant genotype of Staphylococcus aureus subsp. anaerobius isolated from sheep in Sudan
}

\author{
Haitham Elbir ${ }^{1}$, Edward J Feil ${ }^{2}$, Michel Drancourt ${ }^{3}$, Véronique Roux ${ }^{3}$, Sulieman M. El Sanousi ${ }^{4}$, \\ Mona Eshag ${ }^{4}$, Patricia Colque-Navarro ${ }^{5}$, Inger Kühn ${ }^{5}$, Jan-Ingmar Flock ${ }^{5}$ \\ ${ }^{1}$ Department of Microbiology, Tropical Medicine Research Institute, PO BOX 1304 Khartoum 11111, Sudan \\ ${ }^{2}$ Department of Biology and Biochemistry, University of Bath, United Kingdom \\ ${ }^{3}$ Université de la Méditerranée, Marseille, France \\ ${ }^{4}$ Faculty of Veterinary Medicine, University of Khartoum, Sudan \\ ${ }^{5}$ Department of Microbiology, Tumor and Cell Biology, Karolinska Institutet, PO Box 208, 17177 Stockholm, Sweden
}

\begin{abstract}
Background: The aim of the present study was to examine the phenotypic and genotypic relatedness of 17 Staphylococcus aureus subsp. anaerobius isolates recovered from sheep abscesses in Khartoum state, Sudan, during the period 2007-2008.

Methodology: This sample was characterised using antibiogram typing, biochemical typing with the commercial PhenePlate system (PhPCS) and multilocus sequence typing (MLST).

Results: Low levels of resistance were noted to the 11 antimicrobial agents tested. All the isolates corresponded to a single PhP type, and to a single, novel, multilocus sequence type, designated ST1464.

Conclusion: These results demonstrate that the vast majority of cases of sheep abscess disease in Khartoum state are caused by a single novel clone of $S$. aureus subsp. anaerobius.
\end{abstract}

J Infect Dev Ctries 2010; 4(4):235-238.

(Received 30 October 2009 - Accepted 03 February 2010)

Copyright (C) 2010 Elbir et al. This is an open-access article distributed under the Creative Commons Attribution License, which permits unrestricted use, distribution, and reproduction in any medium, provided the original work is properly cited.

\section{Introduction}

Staphylococcus aureus subsp. anaerobius is the etiological agent of a disease in sheep known as Morel's disease, which was first described by Morel in 1911 in France. The disease has been reported from Ethiopia, Kenya, Sudan, Saudi Arabia, Hungary, Spain, and Denmark [1,2,3,4]. The first report of $S$. aureus subsp. anaerobius from a human was in a patient presenting with septicemia, septic arthritis, and multiple pulmonary abscesses to an emergency department in South Australia [5]. Morel's disease is characterized by a large abscess (up to 70 $\mathrm{cm}$ [1]) formed adjacent to or within lymph nodes, mainly in the head, neck and shoulder region. The disease is endemic in nature with high morbidity, but no mortality is directly attributed to it [2].

As sheep constitute a significant proportion of the exported livestock from Sudan, understanding the epidemiology of this disease and implementing effective control measures is of high economic importance. Evidence concerning the diversity of strains causing the disease is currently lacking, but such studies are required for vaccine design. To address this issue we genetically and phenotypically characterised 17 S. aureus subsp. anaerobius strains isolated from sheep abscesses from two distinct locations in Khartoum state.

\section{Material and Methods}

A total of 17 isolates of $S$. aureus subsp. anaerobius were isolated from two different geographic locations in Khartoum state, Sudan, during the period $2007-2008$. The first location was a checkpoint for routine examination of animals entering Khartoum, and the second location was Kadaro Export Abattoir. These two locations represent the main entrance and exit for animals. The bacteria were recovered from the prescapular region. Samples from abscesses were taken aseptically and streaked on sheep blood agar and incubated at $37^{\circ} \mathrm{C}$ in microaerophilic atmosphere for 48 hours. The isolates were verified by Gram staining and biochemical test [6] and sequence analysis of rpoB gene [7]. 


\section{Antimicrobial susceptibility testing}

In vitro antimicrobial susceptibility testing was conducted using a commercially available broth microdilution method (VetMic system; National Veterinary Institute, Uppsala, Sweden). All MIC determinations were performed according to methods described in the Clinical and Laboratory Standards Institute document (CLSI, 2008; formerly NCCLS) [8]. Antimicrobials used in this study were penicillin (0.03-4 $\mu \mathrm{g} / \mathrm{ml})$, Cefalothin $(0.06-8 \mu \mathrm{g} / \mathrm{ml})$, Erythromycin $(0.25-32 \mu \mathrm{g} / \mathrm{ml})$, Chloramphenicol (0.5-64 $\mu \mathrm{g} / \mathrm{ml})$, Clindamycin $(0.2-32 \mu \mathrm{g} / \mathrm{ml})$, Tetracycline $(0.5-64 \mu \mathrm{g} / \mathrm{ml})$, Fusidic acid (0.06-8 $\mu \mathrm{g} / \mathrm{ml})$, Gentamicin (0.5-64 $\mu \mathrm{g} / \mathrm{ml})$, Kanamycin $(0.25-32 \mu \mathrm{g} / \mathrm{ml})$, Oxacillin $(0.12-16 \mu \mathrm{g} / \mathrm{ml})$ and Ciprofloxacin $(0.06-4 \mu \mathrm{g} / \mathrm{ml})$.

\section{Typing of isolates with the PhenePlate (PhP) system}

Biochemical typing of the isolates was performed with the commercial Pheneplate system (PhP-CS and PhP-48 plates; PhPlate Microplate Techniques AB, Stockholm, Sweden). These tests were performed according to instructions from the manufacturer. The test is based on measurements of the kinetics of 24 biochemical reactions [9] performed in microplates. The system generates a quantitative result from each of the 24 tests (a biochemical fingerprint), and can discriminate between hundreds of phenotypes. Briefly, a few colonies were suspended in PhPsuspending media, inoculated onto the PhenePlates, and incubated at $37^{\circ} \mathrm{C}$. The plates were read with an optical microplate reader connected to a computer after 16, 40 and 64 hours of incubation. For the cluster analysis of the PhP-data, the unweighted-pair group method using average linkages (UPGMA) was employed. Isolates with a similarity index greater than 0.975 were considered to be of the same PhPsubtype.

\section{Multilocus Sequence Typing (MLST)}

Genomic DNA was extracted using the boiling method [10]. Seven housekeeping genes were used as described previously [11]. DNA sequencing was performed by Macrogen Inc. (Seoul, South Korea) using BigDye (Applied Biosystems) on a ABI3730XL DNA sequencer (Applied Biosystems). Forward and reverse sequences were aligned using the DNA Baser V2 program. Sequences were then submitted the MLST database (http:/www.mlst.net) for the generation of an allelic profile and sequence type (ST). Concatenated MLST data from representative STs were downloaded from http:// saureus.mlst.net/ and a neighbour-joining tree was reconstructed using the MEGA v.4.2 program.

\section{Genebank accession number}

The DNA sequences of each allele at the seven loci used in this study have been deposited in GenBank under accession number GQ468500 GQ468506 and GQ370468 for rpoB gene.

\section{Results and Discussion}

Here we describe the characterisation of 17 isolates of $S$. aureus subsp. anaerobius isolated from sheep abcesses in the Sudan. The use of a sequencebased typing method, like MLST, facilitated rapid comparisons with other $S$. aureus strains previously typed using this method via the MLST web site (http://saureus.mlst.net). The clustering of isolates obtained by MLST, and the level of discrimination, is largely consistent with that obtained by PFGE $[11,12,13]$.

All the isolates were identical by MLST; thus we found no differences between the isolates recovered from the two sites. All isolates corresponded to a novel allelic profile assigned ST1464 (102-219-204122-13-177-160). The novelty of this clone was not unexpected given the fact that both animal-derived strains, and in particular strains from Africa, are seriously under-represented in the current MLST database. In order to examine the phylogenetic position of this clone within the context of the wider $S$. aureus population, we constructed a neighbourjoining tree using the concatenated sequence ST1464, 18 representative STs from humans (including ST152 which was commonly recovered from human carriage in Mali [14]), and four STs previously characterised from sheep samples (Figure 1). These extra STs were downloaded from the MLST web site. Previous studies have shown that MLST data divide S. aureus into two main clades (group 1 and group 2) [15], and these major groups are evident in the tree in Figure 1. Our analysis suggests that ST1464 is a divergent genotype which loosely clusters with Group 2. The other samples isolated from sheep in the database are divergent both from each other and from ST1464. As reported previously, the Malian clone ST152 also occupies a divergent position and does not belong to either of the main two groups (Figure 1). 
Figure 1. Neighbor-joining tree based on the concatenated sequence of the seven MLST genes. It shows the relationship of ST 1464 and the two main groups of MLST which were shown as group 1 and group 2. STs from sheep samples are marked as black circles and ST1464 from Sudan are marked as the white circle.

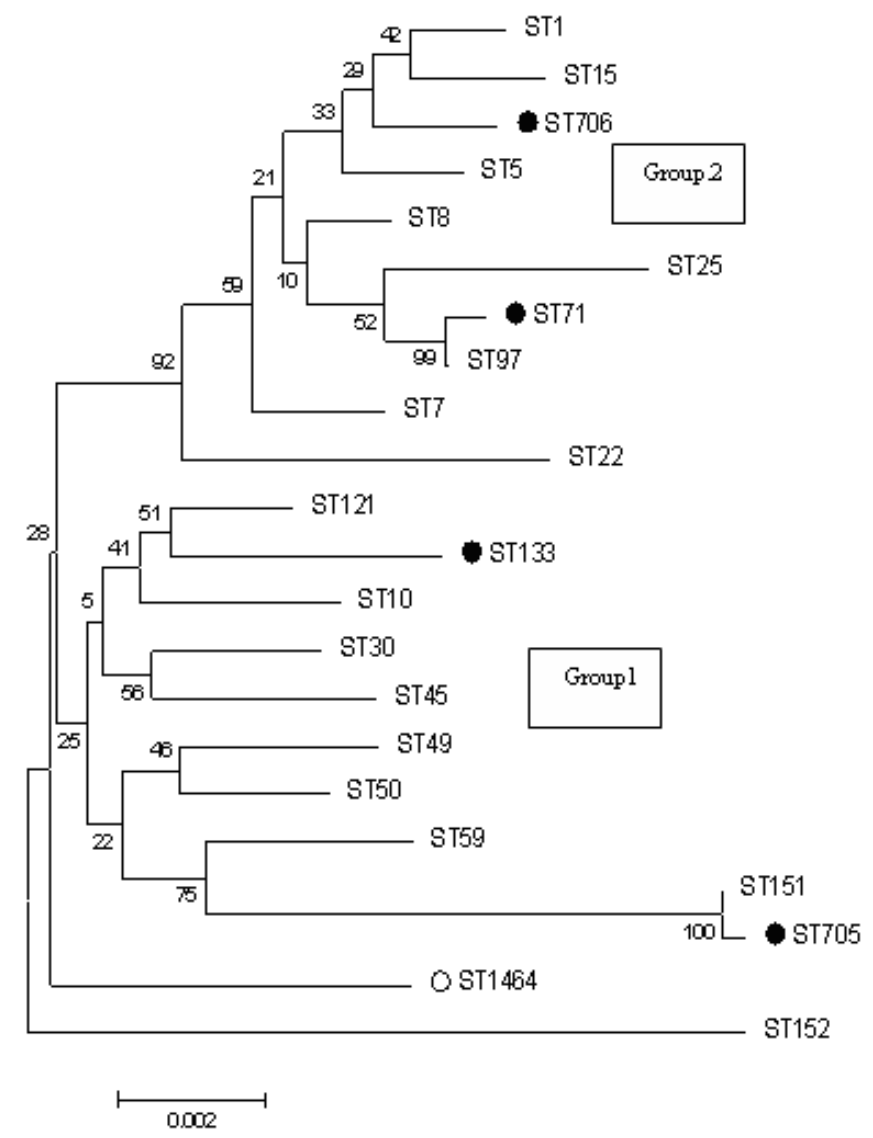

Table 1. Minimum inhibitory concentrations for the 17 S. aureus subsp. anaerobius.

\begin{tabular}{|c|c|c|}
\hline $\begin{array}{c}\text { MIC } \\
\text { [Clinical isolates] }\end{array}$ & $\begin{array}{c}\text { Cut-off values (mg/L) } \\
\text { defining resistance }\end{array}$ & Antimicrobial \\
\hline $0.6-0.12$ & $>1$ & Cefalothin \\
\hline$<\mathbf{0 . 2 5}$ & $>0.25$ & Clindamycin \\
\hline $2-4$ & $>16$ & Chloramphenicol \\
\hline $\mathbf{0 . 2 5}$ & $>1$ & Ciprofloxacin \\
\hline 0.5 & $>1$ & Erythromycin \\
\hline$<0.5$ & $>1$ & Tetracycline \\
\hline $0.12-0.25$ & $>0.5$ & Fusidic acid \\
\hline 2 & $>2$ & Gentamicin \\
\hline 8 & $\mathbf{8}>$ & Kanamycin \\
\hline $0.25-0.5$ & $>2$ & Oxacillin \\
\hline$<0.03$ & $>1$ & penicillin \\
\hline
\end{tabular}


The MLST database is based largely on isolates from Europe, the United States of America, Australia and Japan, whereas Africa and mainland Asia are under-represented. Furthermore, although an increasing number of isolates from non-human hosts have been characterised in recent years (mostly bovine isolates), there remain very few data for isolates from sheep. More representative samples are therefore required to shed light on the global diversity of this species. Although MLST is a very useful method for global epidemiology and population studies, it is possible that other typing methods may reveal variation within single MLST genotypes. In order to check for variation within the ST1464 clone, we further typed the isolates by biochemical typing (e.g. PhP) and antibiogram typing. All the isolates were susceptible to 11 antimicrobial agents tested listed in Table 1, and biochemical typing revealed that all the isolates belong to a single $\mathrm{PhP}$ type. These observations support the view that the majority of sheep abscesses in Khartoum are caused by a single clone which is genetically and phenotypically invariant. This may reflect the recent introduction and rapid spread of this clone, though a high rate of sheep-to-sheep transmission within a single herd, and it is possible that this clone is well adapted to persist in the ovine host. This finding also raises the possibility of the development of a high specificity vaccine against this clone.

In conclusion ST1464 is a dominant clone from sheep abscesses in Khartoum. This study contributes to the understanding of the epidemiology of the disease which is important for control of sheep abscess and for vaccine design.

\section{Acknowledgments}

The authors thank the Karolinska Institute in Sweden for financial support. This study was conducted at the Department of Microbiology, Tumor and Cell Biology.

\section{References}

1. Alhendi AB, al-Sanhousi SM, al-Ghasnawi YA, Madawi M (1993) An outbreak of abscess disease in goats in Saudi Arabia. Zentralbl Veterinarmed 40: 646-51.

2. Bajmocy E, Fazekas B, Tanyi J (1984) An outbreak of Morel's disease (a contagious sheep disease accompanied by abscess formation) in Hungary. Acta Vet Hung 32: 9-13.

3. De la Fuente R, Suarez G, Schleifer K H (1985) Staphylococcus aureus subsp. anaerobius subsp. nov., the causal agent of abscess disease of sheep. Int J Syst Bacteriol 35: 99-102.

4. Moller K, Agerholm JS, Ahrens P, Jensen NE, Nielsen TK (2000) Abscess disease, caseous lymphadenitis, and pulmonary adenomatosis in imported sheep. J Vet Med B Infect Dis Vet Public Health 47: 55-62.

5. Sandra L Peake, John, Victor, Peter., Louisa, Chan., Rolf, P. Wise., Andrew, R. Butcher., David, I. Grove (2006) First Report of Septicemia Caused by an Obligately Anaerobic Staphylococcus aureus Infection in a Human. J Clin Microbiol 44: 2311-2313.

6. Bannerman TL (2003) Staphylococcus Micrococcus and other catalase-positive cocci that grow aerobically. In Manual of Clinical Microbiology, 8th ed. Edited by Murray PR, Baron EJ, James HJ, Pfaller MA and Yolken RH. Washington, DC: American Society for Microbiology. pp.388.

7. Drancourt M and Raoult D (2002) rpoB gene sequencebased identification of Staphylococcus species. J Clin Microbiol 40: 1333-1338.

8. Clinical Laboratory Standards Institute (2008) Performance Standards for Antimicrobial Disk Dilutin Susceptibility Tests for Bacreria Isolated From Approved Standard. Third Edition M31-A3. CLSI, Waune, PA, USA.

9. Björkqvist M, Söderquist B, Törnqvist E, Sjöberg L, Fredlund H, Kühn I, Colque-Navarro P, Schollin J (2002) Phenotypic and genotypic characterisation of blood isolates of coagulase-negative staphylococci in the newborn. APMIS 110: 332-9.

10. Reischl U, Linde HJ, Metz M, Leppmeier B, Lehn N (2000) Rapid identification of methicillin-resistant Staphylococcus aureus and simultaneous species confirmation using realtime fluorescence PCR. J Clin Microbiol 38: 2429-33.

11. Enright MC, Day NP, Davies CE, Peacock SJ, Spratt BG (2000) Multilocus sequence typing for characterization of methicillin-resistant and methicillin-susceptible clones of Staphylococcus aureus. J Clin Microbiol 38: 1008-15.

12. Schmitz F-J, Steirt M, Tichy H-V, Hofmann B, Verhoef J, Heinz H-P, Köhrer K, Jones ME (1998) Typing of methicillin-resistant Staphylococcus aureus isolates from Dusseldorf by six genotypic methods. J Med Microbiol 47: 341-51.

13. Streulens MJ, Bax R, Deplano A, WG, van Belkum A (1993) Concordant clonal delineation of methicillin-resistant Staphylococcus aureus by macrorestriction analysis and polymerase chain reaction genome fingerprinting. J Clin Microbiol 31: 1964-970.

14. Ruimy R, Maiga A, Armand-Lefevre L, Maiga I, Diallo A, Koumare AK, Ouattara K, Soumare S, Gaillard K, Lucet JC, Andremont A, Feil EJ (2008) The carriage population of Staphylococcus aureus from Mali is composed of a combination of pandemic clones and the divergent PantonValentine leukocidin-positive genotype ST152. J Bacteriol 190: 3962-968.

15. Cooper JE, and Feil EJ (2006) The phylogeny of Staphylococcus aureus: which genes make the best intraspecies markers? Microbiology 152: 1297-305.

\section{Corresponding author}

Haitham Elbir

Department of Microbiology, Tropical Medicine Research Institute. P.O. BOX 1304 Khartoum 11111, Sudan

Email: mbahgatriad@yahoo.com

Conflict of interest: The authors declare no conflicts of interest. 